\title{
Maternal serum progesterone level in preeclampsia
}

\author{
Shiuly Chowdhury, Jannatul Ferdous, Khadiza Nurun Nahar and Sharmeen Mahmood
}

\author{
Article Info \\ Department of Obstetrics and Gynecolo- \\ gy, Faculty of Surgery, Bangabandhu \\ Sheikh Mujib Medical University, \\ Shahbag, Dhaka, Bangladesh

$\begin{aligned} & \text { For Correspondence: } \\ & \text { Shiuly Chowdhury } \\ & \text { shiuly07@yahoo.com }\end{aligned}$
$\begin{array}{lr}\text { Received: } & \text { 18 November } 2019 \\ \text { Accepted: } & 28 \text { January } 2020 \\ \text { Available Online: } & \text { 19 February 2020 }\end{array}$

ISSN: 2224-7750 (Online) 2074-2908 (Print)

DOI: 10.3329/bsmmuj.v13i1.45052

Keywords: Maternal; Preeclampsia progesterone; Testosterone; Dehydroepiandrosterone

Cite this article:

Chowdhury S, Ferdous J, Nahar KN, Mahmood S. Maternal serum progesterone level in preeclampsia. Bangabandhu Sheikh Mujib Med Univ J. 2020; 13: 9 12.

\section{Copyright:}

The copyright of this article is retained by the author(s) [Atribution CC-By 4.0]

Available at:

www.banglajol.info

A Journal of Bangabandhu Sheikh Mujib Medical University, Dhaka, Bangladesh

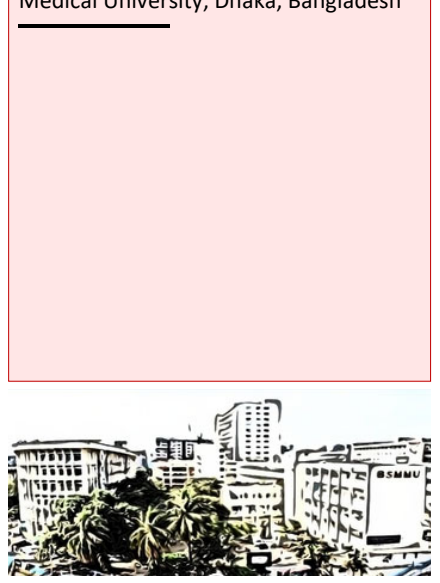

\section{Abstract}

This study was performed to find out a relationship between the levels of progesterone with $(n=30)$ and without $(n=48)$ preeclampsia. The age and body mass index of the participants along with their gestational age, gravidity and parity were harmonized. The serum progesterone and serum androgens such as total testosterone, free testosterone, and dehydroepiandrosterone sulfate levels were investigated. The results revealed that although the serum progesterone level was significantly low among the participants with preeclampsia $(182.7 \pm 29.4 \mathrm{vs} 281.7 \pm 16.2 \mathrm{ng} / \mathrm{mL}$; $\mathrm{p}<0.001$ ) but the total and free testosterone levels were found to be significantly higher than the healthy normotensive participants $(2.5 \pm 0.6$ vs. $1.9 \pm 0.1 \mathrm{nmol} / \mathrm{dL} ; \mathrm{p}=0.041$ and $2.2 \pm 0.3 \mathrm{vs} .1 .4 \pm$ $0.2 \mathrm{pg} / \mathrm{mL}$, respectively, $\mathrm{p}=0.035$ ). In conclusion, the serum progesterone level was low in pregnant women having preeclampsia.

\section{Introduction}

Preeclampsia is a multiorgan disease process of unknown etiology.. It is a temporary yet potentially severe gestational complication, 2 and is characterized by high blood pressure, increase in urinary protein, and fluid retention in the body. This pregnancy event may necessitate early delivery, either spontaneous or induced in most of the cases. Generally, preeclamptic woman recovers shortly after birth, but early delivery raises the baby's risk of complications. This must be balanced against delay, which increases the risk of developing eclampsia, with seizures and organ damage like renal failure with substantial risks for the mother and her fetus life. $\frac{3-5}{-5}$

The prevalence and complications of preeclampsia were also investigated by some of the previous researches. Although $2-5 \%$ of the pregnant women had preeclampsia, the incidence increased from 10 to $18 \%$ among the developing countries. 6 Furthermore, the death rate was also high (approximately 18\%).? The complications include increased maternal and fetal morbidity or mortality along with the premature delivery and the need for the neonatal intensive care unit. Furthermore, 10 to $20 \%$ of women with severe preeclampsia also develop hemolysis, elevated liver enzymes, and low platelet count. $\underline{8}$ Therefore, many investigators have focused their research on the early diagnosis of preeclampsia, the changes of hormones and associated etiology.

Regarding the etiology of preeclampsia although many studies have reported that there was an increase of androgen levels,, 10 but others have claimed that there were no changes in the levels of androgens. These hormones do not play a clinically significant role in the disease pathogenesis.11 Progesterone, on the other hand, is considered as an important steroid hormone which is considered responsible for the vascular resistance during childbirth.12 An animal study also reported that progesterone injection in rat induced preeclampsia reduced the blood pressure. 13 Furthermore, a clinical study has indicated that the administration of progesterone during pregnancy could reduce both systolic and diastolic blood pressure. There was a marked increase in urine production, an improvement of edema, a slight drop in weight gain, but no change in the proteinuria. $\underline{14}$ Moreover, van Veen et al. (2015) $\underline{15}$ isolated the human artery from non-pregnant, normotensive women and preeclamptic pregnant women that showed that progesterone has a specific in vitro effect on the human omental artery. Changes in the vascular tolerance to endogenous hormones (angiotensin II, catecholamine and vasopressin) and the absence or decrease in the concentration of nitric oxide that plays an important role in raising blood pressure were observed in preeclampsia.16,17 The thromboxane $\mathrm{A} 2 /$ prostacyclin ratio was also found to be increased in preeclampsia. 17 The vascular relaxing effect of progesterone is likely to improve these effects. The vascular relaxing effect of progesterone may depend on the release of prostacyclin or nitrite oxide. 18 Another important mechanism for the antihypertensive character of progesterone is the direct effect of blocking calcium channels on 
Table I

Association of serum androgens and progesterone with preeclampsia

\begin{tabular}{|lcrr|}
\hline Hormone parameters & $\begin{array}{c}\text { Without } \\
\text { preeclampsia } \\
(\mathrm{n}=48)\end{array}$ & $\begin{array}{c}\text { With } \\
\text { preeclampsia } \\
(\mathrm{n}=30)\end{array}$ & $\begin{array}{c}\mathrm{p} \\
\text { value }\end{array}$ \\
\hline Serum progesterone $(\mathrm{ng} / \mathrm{mL})$ & $281.7 \pm 16.2$ & $182.7 \pm 29.4$ & $<0.001$ \\
Total testosterone $(\mathrm{nmol} / \mathrm{L})$ & $1.9 \pm 0.1$ & $2.5 \pm 0.6$ & 0.041 \\
Free testosterone $(\mathrm{pg} / \mathrm{mL})$ & $1.4 \pm 0.2$ & $2.2 \pm 0.3$ & 0.035 \\
$\begin{array}{l}\text { Dehydroepiandrosterone } \\
\text { sulfate }(\mu \mathrm{g} / \mathrm{dL})\end{array}$ & $74.7 \pm 7.9$ & $63.3 \pm 10.7$ & 0.391 \\
\hline
\end{tabular}

vascular muscles. $\underline{19}$

Based on the previous animal and clinical studies, a question could arise whether or not there is a correlation between the serum levels of androgen and progesterone in patients with preeclampsia, which is needed to be justified. Therefore, the present study was performed to investigate the relationship between the serum levels of androgen and progesterone in patients with and without preeclampsia.

\section{Materials and Methods}

This case-control study was performed at the Department of Obstetrics and Gynecology of Bangabandhu Sheikh Mujib Medical University and Dhaka Medical College Hospital from July 2012 to June 2013.

A total of 78 participants who had third-trimester pregnancy were selected by purposive sampling technique. The participants with preeclampsia (systolic blood pressure $\geq 140$ and/or diastolic blood pressure $\geq 90$ with dipstick proteinuria $1+$ or more) were used as an experimental group $(n=30)$, while the healthy normotensive participants (systolic and diastolic blood pressures were $<140$ and/or $<90 \mathrm{~mm}$ $\mathrm{Hg}$ respectively) were selected as a control group $(n=48)$. Pregnant women with the history of hypertension and proteinuria before 20 weeks of gestation or known history of hypertension before gestation, associated with any known systemic disorders (diabetes mellitus, chronic renal disease, essential hypertension, liver disease, autoimmune disease, heart disease, epilepsy, coagulation disorder), with known history of polycystic ovarian syndrome or any other hormone disorders, receiving hormone therapy were excluded from the study. The demographic and anthropometric variables studied were age, socio-economic status, weight, and height. The obstetrical variables were gestational age, gravida, parity and biochemical parameters that included serum progesterone, total testosterone, free testosterone and dehydroepi-androsterone sulfate.

\section{Laboratory procedure}

Venous blood $(5 \mathrm{~mL})$ samples were collected from the antecubital vein, labeled and sent to the laboratory of Biochemistry. The serum or plasma (with EDTA or heparin) samples were used. The collected samples were stored up to 7 days at $2-8^{\circ} \mathrm{C}$ or 4 weeks at $-20^{\circ} \mathrm{C}$.

The levels of progesterone, testosterone (total and free) and dehydroepiandrosterone were determined using the standard methods (measurement of serum progesterone and testosterone by VITROS immunodiagnostic system. Measurement of serumfree testosterone by ELISA and measurement of serum dehydroepiandrosterone sulfate by Architect DHEAS).

\section{Statistical analysis}

Data were analyzed by using computer software SPSS (Statistical Package for Social Sciences, version 17) and statistical analysis was performed by Chisquared $\left(X^{2}\right)$ test for the comparison of data presented in categorical scale and two-tailed Student's ttest for comparison of data presented on a continuous scale. The $\mathrm{p}$ value of $<0.05$ was considered statistically significant.

\section{Results}

The mean age and socio-economic condition of the participants with or without preeclampsia were 27.1 \pm 5.2 years and $25.8 \pm 4.5$ years, respectively $(\mathrm{p}=$ 0.271 ) and 53.3 and $72.9 \%$ belonged to the middle class. The body mass index of $46.7 \%$ from the experimental group and $41.7 \%$ from the control group were $\geq 25 \mathrm{~kg} / \mathrm{m}^{2}$, respectively. The differences between the two groups were not statistically significant $(\mathrm{p}=0.665)$.

In terms of gestational age, $86.7 \%$ in the experimental group and $72.9 \%$ in the control group were preterm $(<37$ weeks of gestation) $(p=0.152)$. In terms of gravidity, the majority of the cases $(66.7 \%)$ and controls $(64.6 \%)$ were multigravida. A few in either group were grand multipara $(p=0.832)$. There was no significant difference between the study groups with concerning to parity $(\mathrm{p}=0.820)$.

The results of serum progesterone level was significantly low among the participants with preeclampsia $(182.7 \pm 29.4$ vs $281.7 \pm 16.2 \mathrm{ng} / \mathrm{mL}$; $\mathrm{p}<0.001)$ but the total and free testosterone levels were found to be significantly high among the participants with preeclampsia than the healthy normotensive participants $(2.5 \pm 0.6$ vs. $1.9 \pm 0.1$ $\mathrm{nmol} / \mathrm{dL} ; \mathrm{p}=0.041$ and $2.2 \pm 0.3$ vs. $1.4 \pm 0.2 \mathrm{pg} / \mathrm{mL}$, respectively, $\mathrm{p}=0.035$ ) (Table I). Furthermore, there was no significant difference between the groups concerning to the serum dehydroepiandrosterone sulfate $(\mathrm{p}=0.391)$. 


\section{Discussion}

In the present study, serum progesterone was significantly low in the preeclamptic women compared to their control counterparts. This study was consistent with the study conducted by Edelstam et al. (2007)르 that serum progesterone levels were found to be considerably low in women with preeclampsia compared to the healthy pregnant women with similar body mass index and gestational age. The reduction of serum progesterone might be due to the impairment of placental function in participants with preeclampsia. This is also supported by Wan et al. (2018).21 The role of progesterone changes in animals as the cause of preeclampsia has also been demonstrated by the research studies. Subcutaneous injection of progesterone into a pregnant mouse with preeclampsia decreases the blood pressure in an experimental study. $\underline{13} \mathrm{~A}$ study where progesterone is considered to lower blood pressure has shown the omental vascular relaxing effect of progesterone in pregnant women. As the level of progesterone in preeclampsia is decreased, the relaxing effect on the vascular smooth muscle is hindered and there is a consequent increase of the blood pressure. 15

The present study also confirmed that the total and free testosterone levels were considerably high in the preeclamptic participants than the participants without preeclampsia. However, no significant differences were found with respect to dehydroepiandrosterone sulfate. The result found in the present study had similarities and dissimilarities with that of previous studies. Serin et al.(2001)22 revealed that in the third trimester of preeclamptic participants, the total and free testosterone levels were markedly high compared to participants without preeclampsia. The level of androstenedione between the two groups were not significantly different in their analysis. Wan et al. (2018)1ㅡ also reported that total and free testosterone levels of preeclamptic participants were considerably high than the participants without preeclapmsia. There was no significant difference between the two classes in dehydroepiandrosterone sulfate. In preeclamptic women, Laivuori et al. (1998) 9 also found that the free testosterone level was higher than the normotensive women. On the other hand, Edelstam et al. (2007) 20 observed that free testosterone level was significantly low in preeclamptic women than in the normotensive women and there was no difference in the total testosterone and dehydroepiandrosterone sulfate levels between the groups.

Indirect evidence suggests that androgens have significant effects on vascular reactivity in ways like renin-angiotensin system, eicosanoids, and platelets in reported preeclampsia. $.23,24$ It has also been found recently that in patients with preeclampsia serum concentrations of inhibin A were increased than in control subjects with matched pregnancies. This result was interpreted as further proof of trophoblastic dysfunction and its usefulness as a predictor of preeclampsia. Furthermore, in woman inhibin increases androgen levels in circulation. $\underline{25}$ Thus, the effects of increased serum inhibin in preeclampsia may be manifested by increased levels of circulating androgen. Laivuori et al. (1998) 9 compared the free testosterone level between prior preeclampsia and normal controls and found that a history of preeclampsia, an average of 17 years earlier, was associated with high levels of free testosterone that should be considered as indirect evidence of preeclampsia association with altered serum androgens levels. 9 In addition, some other studies have shown that hypertension is associated with high levels of androgen in non-pregnant healthy women. $\frac{5,25,26}{2}$ The exact mechanism underlying preeclampsia is still to be defined despite extensive research. Until preeclampsia pathogenesis is well-defined, effective preventive strategies are unlikely to be developed. So, to evaluate the association of low level of progesterone in preeclamptic women, further randomized control studies are required.

\section{Conclusion}

Serum progesterone level is reduced in pregnant women having preeclampsia.

\section{Ethical Issue}

This research was approved by the Institutional Review Board of Bangabandhu Sheikh Mujib Medical University (Ref. No. 13816/2012) and the Ethical Committee of Dhaka Medical College (Ref. No. 158/2013)

\section{Conflict of Interest}

Authors declare no conflict of interest.

\section{References}

1. Uzan J, Carbonnel M, Piconne O, Asmar R, Ayoubi J. Preeclampsia: Pathophysiology, diagnosis, and management. Vasc Health Risk Manag. 2011; 7: 467 -74 .

2. Ramos JGL, Sass N, Costa SHM. Preeclampsia. Rev Bras Ginecol Obstet. 2017; 39: 496-512.

3. Williams PJ, Gumaa K, Scioscia M, Redman CW, Rademacher TW. Inositol phosphoglycan P-type in preeclampsia: A novel marker. Hypertension 2007; 49: 84-89. 
4. Khanam S, Fatima P, Nasrin B, Hoque MM. Association of anticardiolipin IgM antibody with preeclampsia. Bangabandhu Sheikh Mujib Med Univ J. 2018; 11: 126-29.

5. Nahar K, Islam F, Khan NA. Relationship between severity of hypertension and renal impairment in preeclampsia. Bangabandhu Sheikh Mujib Med Univ J. 2018; 11: 213-17.

6. Ghulmiyyah L, Sibai B. Maternal mortality from preeclampsia/eclampsia. Semin Perinatol. 2012; 36: 56-59.

7. Goldenberg RL, Culhane JF, Iams JD, Romero R. Epidemiology and causes of preterm birth. Lancet 2008; 371: 75-84.

8. Trottmann F, Baumann M, Amylidi-Mohr S, Surbek D, Risch L, Mosimann B, Raio L. Angiogenic profiling in HELLP syndrome cases with or without hypertension and proteinuria. Eur J Obstet Gynecol Reprod Biol. 2019; 243: 93-96.

9. Laivuori H, Kaaja R, Rutanen EM, Viinikka L, Ylikorkala O. Evidence of high circulating testosterone in women with prior preeclampsia. J Clin Endocrinol Metab. 1998; 83: 344-47.

10. Perusquía M, Hanson AE, Meza CM, Kubli C, Herrera N, Stallone JN. Antihypertensive responses of vasoactive androgens in an in vivo experimental model of preeclampsia. Steroid J Biochem Mol Biol. 2018; 178: 65-72.

11. Miller NR, Garry D, Cohen HW, Figueroa R. Serum androgen marker in preeclampsia. J Reprod Med. 2003; 48: 225-29.

12. Tamimi R, Lagion P, Vatten LJ. Pregnancy hormones, preeclampsia and implication for breast cancer risk in the offspring: Cancer epidemiology, biomarker and prevention. N Engl J Med. 2003; 12: 647-50.

13. Lauszus FF. Preeclampsia prediction in type I diabetes and diurnal blood pressure methodology. Curr Hypertens Rev. 2016; 12: 127-33.

14. Zhang Q, Huang $Y$, Zhang $K$, Yan $Y$, Wu J, Wang F, Zhao Y, Xu H, Jiang W, Yu D, Chen Y, Ye D. Progesterone attenuates hypertension and autoantibody levels to the angiotensin II type 1 receptor in response to elevated cadmium during pregnancy. Placenta 2018; 62: 16-24.

15. van Veen TR, Panerai RB, Haeri S, Zeeman GG, Belfort MA. Effect of breath holding on cerebrovascular hemodynamics in normal pregnancy and preeclampsia. J Appl Physiol. 2015; 118: 858-62.
16. Chutatape A, Teoh WH. Third nerve palsy associated with preeclampsia and HELLP syndrome. J Anesth. 2013; 27: 757-60.

17. Lambert G, Brichant JF, Hartstein G, Bonhomme V, Dewandre PY. Preeclampsia: An update. Acta Anaesthesiol Belg. 2014; 65: 137-49.

18. Sartin JL, Elsasser TH, Kahl S, Baker J, Daniel JA, Schwartz DD, Steele B, Whitlock BK. Estradiol plus progesterone treatment modulates select elements of the proinflammatory cytokine cascade in steers: Attenuated nitric oxide and thromboxane B2 production in endotoxemia. J Anim Sci. 2003; 81: 1546-51.

19. Kahl S, Elsasser TH, Li CJ. Modeling the effects of estradiol and progesterone on the acute phase proinflammatory axis: Variability in tumor necrosis factor- $\alpha$, nitric oxide, and xanthine oxidase responses to endotoxin challenge in steers. Domest Anim Endocrinol. 2011; 40: 213-21.

20. Edelstam G, Karlsson C, Westgren M, Löwbeer C, Swahn ML. Human chorionic gonadatropin (hCG) during third trimester pregnancy. Scand J Clin Lab Invest. 2007; 67: 519-25.

21. Wan J, Hu Z, Zeng K, Yin Y, Zhao M, Chen $\mathrm{M}, \mathrm{Chen} \mathrm{Q}$. The reduction in circulating levels of estrogen and progesterone in women with preeclampsia. Pregnancy Hypertens. 2018; 11: 18-25.

22. Serin IS, Kula M, Basbug M, Unluhizarci K, Gucer S, Tayyar M. Androgen levels of preeclamptic patients in the third trimester of pregnancy and six weeks after delivery. Acta Obstet Gynecol Scand. 2001; 80: 1009-13.

23. Bachmann J, Feldmer M, Ganten U, Stock G, Ganten D. Sexual dimorphism of blood pressure: Possible role of the rennin-angiotensin system. J Steroid Biochem Mol Biol. 1991; 40: 511-15.

24. Johnson M, Ramey E, Ramwell PW. Androgenmediated sensitivity in platelet aggregation. Am J Physiol. 1977; 232: 381-85.

25. Pigny P, Cortet-Rudclli G, Duhanell A, Deroubaix Allard D, Racadot A, Dewilly D. Serum a-inhibin levels in polycystic ovarian syndrome: Relationship to the serum andorstenedione level. J Clin Endocrinol Metab. 1997; 82: 1939-43.

26. Mantzoros CS, Georgiadis EI, Young R, Evagelopoulou C, Khoury S, Katsilambros N, Sowers JR. Relative androgenicity, blood pressure levels and cardiovascular risk factors in young healthy women. Am J Hypertens. 1995; 8: 606-14. 